The maintenance of a central database of burns units and practitioners forms part of this strategy. Broader objectives include the improvement of burns care and resources in South Africa and increasing the number of practitioners to complete the Emergency Management of Severe Burns (EMSB) course.

1. Benzaquin P. Fire in Boston's Coconut Grove. Boston: Braden Press, 1959

2. Clive Wood, ed. Accident and Emergency Burns: Lessons from the Bradford Disaster. Royal Society of Medicine Services Round Table Series. Number 3. London: Royal Society of Medicine, 1987:51103 .

3. Barilo DJ, Wolf S. Planning for burn disasters: Lessons learned from one hundred years of history. Burn Care Res 2006; 27(5):622-634

4. McGregor JC. Major burn disasters: lessons to be learned from previous incidents and a need for a national plan. Surg J R Coll Edin Ire 2004;2(5):249-311.

5. Greenwood JE, Mackie IP. Factors for consideration in developing a plan to cope with mass burn casualties. ANZ J Surg 2009;79(9):581-583.
6. Wachtel TL, Dimick AR. Burn Disaster Management. In: Herndon DN, ed. Total Burn Care. Philadelphia: WB Saunders, 1998:19-32.

7. Hovarth J. Ausburnplan - Australian Mass Casualty Burn Disaster Plan. 2005. http://www.health gov.au/internet/wcms/publishing.nsf/Content/phd-health-emergency.htm (accessed 16 February 2010)

8. ABA Board of Trustees. Committee on Organization and Delivery of Burn Care. Disaster management and the ABA Plan. J Burn Care Rehabil 2005:26(2):102-106. 9. Haberal M. Guidelines for Dealing with Disasters involving Large Numbers of Extensive Burns.
International Society for Burns Injuries. www.burndisaster.com/isbi\%20disaster\%20manual.pdf (accessed 22 February 2010).

10. American College of Surgeons. Advanced Trauma Life Support (ATLS) for Doctors Course Manual. 8th ed. Chicago: American College of Surgeons, 2008.

11. Karpelowsky JS, Wallis L, Madaree A, Rode H. South African Burn Society burn stabilisation protocol. S Afr Med J 2007;97(8):574.

12. Chim H, Yew WS, Song C. Managing burn victims of suicide bombing attacks: outcomes, lessons learnt, and changes made from three attacks in Indonesia. Critical Care 2007;11(1):R15.

13. Australia and New Zealand Burn Association. Emergency Management of Severe Burns (EMSB) Course Pre-reading. Brisbane, Australia: Australia and New Zealand Burn Association, 1996.

\title{
ISSUES IN MEDICINE Ethical decision making in severe paediatric burn victims
}

H Rode, A J W Millar, B Castle, J Lyle

'The life of a patient is the only life the patient has - can we really make a judgment call on who to treat or not?' J Puchula (from his address at the 2008 congress of the European Club for Paediatric Burns, Gdansk).

The matter of triaging severe burns so that expensive and potentially futile treatment should not be initiated was discussed in a priority setting process by the Western Cape Health Department, and led us to question the validity of such an approach.

The provision of equitable, accessible and appropriate burn care in South Africa faces many problems, particularly for patients with major burns. Approximately $3.2 \%$ of South Africa's population suffer burns annually, of whom $50 \%$ are less than 20 years of age, and burns are the leading cause of unnatural death under the age of 5 (personal communication - M Pedan, MRC). ${ }^{1}$ Burn care in South Africa varies enormously in terms of clinical management, organisation, facilities, staffing, workload and outcomes. Care of the burnt child is entirely emergency driven, labour intensive, has an appreciable morbidity and mortality, and experiences the same economic pressures as the rest of health care.

Heinz Rode is Emeritus Professor of Paediatric Surgery at Red Cross War Memorial Children's Hospital and the University of Cape Town; Alastair Millar is Charles FM Saint Professor and Head of the Paediatric Surgery Department, Red Cross War Memorial Children's Hospital and the University of Cape Town; Bernice Castle is a clinical psychologist and specialist educationalist in private practice in Cape Town; and Jeff Lyle is a pre-medical student, University of North Carolina, USA.
Driven by fiscal restraints and the need to ration resource allocations, health authorities are driving to rationalise medical care by means of standard protocols. Therefore, it would be prudent to re-evaluate the management and outcome of major paediatric burns in South Africa, emphasising the development of criteria for an explicit and accountable health care approach. ${ }^{2,3}$ The protocols should include a fair, ethical, equitable and reasonable process for the management of the burnt patient with little or no hope of survival.

Our case study below highlights the moral and ethical questions posed by a patient sustaining very severe burns in relation to advances in burn care. The moral dilemma is that while survival could be achieved, it might result in a disfigured, deformed and disabled person with poor quality of life. Would this be acceptable or justified in a limited health resource environment? ${ }^{4}$

\section{Case history}

A 9-year-old girl sustained $94 \%$ total body surface burns (TBSA) following a gas explosion, with $75 \%$ of the burns full thickness and with a significant inhalation component. She was resuscitated following standard protocols. ${ }^{5}$ Multiple complications during her in-hospital treatment included burn wound infections, pneumonia, pleural effusion, broncho-pleural fistula, and 6 episodes of sepsis; 25 surgical procedures -14 within the first month during a hospital stay of 107 days - were required, including emergency escharotomies, eschar debridement, procurement and application of allograft, biological skin substitutes, cultured epithelial autographs and use of autografts. Enteral feeding provided her nutritional needs, also during surgical procedures to maintain requirements. She received active and passive physiotherapy and occupational therapy throughout her hospitalisation. During this period, she was isolated and attended to by only her immediate family. Before discharge, she was entered into an intense and all-embracing physical and psychosocial rehabilitation programme. Although left with an altered body image, scarred facial features and significant physical impairment, her introduction into mainstream activities progressed over months and years. 


\section{The problem on admission}

We were confronted with a child with major life-threatening burns, and at that stage did not know whether or not the situation was hopeless and additional care beyond comfort measures futile. The family unit was broken, with the father in a critical condition in another hospital and the child legally incompetent regarding consent. Candid discussions were held with the mother outlining the chances of survival (less than 10\%), the anticipated course of treatment and what could be expected long-term should treatment be continued. The finality of a decision to withdraw treatment made the choice agonising for all. However, the patient responded well to resuscitation, was conscious and had a concerned and caring mother. This made us favour an aggressive treatment programme.

\section{Guidelines for medical intervention}

Burn care outcomes have substantially improved over the past 3 decades. ${ }^{6,7}$ Although there are mathematical models to predict outcomes, clinical experience with major burns over 30 years helped us in deciding our course of action, using the following processes/ considerations.

\section{Medical considerations}

Survival from a major burn is determined by events occurring after the injury. Factors affecting outcome traditionally include site of the burn incident, injury characteristics, rapidity of transport to hospital, therapeutic measures including the quality of resuscitation, infection control, early wound closure, inhalation injury management, nutrition and acute rehabilitation. Outcome cannot consistently be predicted from these factors alone. ${ }^{6-10}$ Therefore, the consensus among burn surgeons is that severely burnt children should be given a course of treatment in a facility of their experience and in their care before the futility of further treatment can be considered. The concept of 'survivability' changes with more experience, and the focus therefore must be on realistic expectations at every stage. National figures for burn survival are not known in South Africa, but in our experience it is very unlikely that a patient with burns exceeding $85 \%$ TBSA could survive.

\section{Administrative considerations}

With the ever-increasing demand for more and improved services and crippling fiscal constraints, available resources must be rationalised and allocated fairly and transparently. The overall goal is to maximise health benefits within society. ${ }^{11}$ This process is actively driven by the Western Cape Department of Health., ${ }^{2,11,12}$ Therapy for major burn patients is regarded as very expensive and its cost-effectiveness is questioned. Prevailing opinion is that patients with very severe burns do not survive and, if they do, are left with very poor quality of life. This issue has confronted burn surgeons with very difficult choices: is it acceptable to withhold or withdraw essential treatment in the critically burnt patient? Withdrawal of treatment for the severely burnt elderly patient has wide acceptance. However, there are no guidelines for children. The dilemmas that confront burn surgeons include who decides, what practical and/or ethical guidelines are to be used, and how to define futility in the light of technological advances and readily available but extremely expensive artificial skin substitutes. ${ }^{13,14}$

The approach that was decided for our patient centred on our clinical experience and bedside negotiations. Modern burn care could ensure that children predicted to die by classic criteria of age, burn size and the presence of inhalation injuries, can now survive with a reasonable quality of life. ${ }^{15,16}$ Until it can be proven that a patient with a major burn has no chance of survival - and there are no acceptable criteria regarding cost-benefit, or specific protocols (cf. renal dialysis and renal transplantation) - it would be prudent to embark on treatment. Hopeless situations include children who have sustained destructive face and hand burns simultaneously with irreversible brain hypoxaemic injury and multi-organ failure.

\section{Financial implications}

Maximising resource allocation demands constant economic analysis of therapeutic modalities. ${ }^{17}$ However, there are few reliable data on the management cost of paediatric burns.

The development of a fiscal framework for the fair management of a major burn patient must meet societal preferences and values. ${ }^{11}$ What is quite clear to us is that decisions should only be made by health professionals with experience in the care of major burns. This process has been developed for end-stage renal failure and implemented with success.

\section{Ethical considerations}

Each burn patient is unique, with a complex injury and possible pre-existing diseases and ongoing pathophysiology. The first and foremost guideline in the case under discussion was that she had the right to the best decision by weighing the risks and benefits, assessing the complications such as disability and/or disfigurement, and taking into account the subsequent quality of life or even death. ${ }^{4,18}$ She could not understand, communicate or reason about her immediate care and was legally incompetent. Surrogate guardians therefore had to decide on her 'best interest' regarding futility or active management. Her parents (specifically her mother) were in the best position to advise/decide in consultation with the treating physicians. Equally important was the co-operative effort among the team of medical professionals working with her: doctors, interns, nurses, physiotherapists, occupational therapists, psychologists and social workers provided their expertise.

The main question, however, was that while survival might be possible, was it desirable in terms of quality of life? Would treating her be meaningful? If treatment were not instituted, the alternative would have been death. The Royal College of Paediatric and Child Health (RCPCH) has defined situations where withdrawal of treatment is 'practical and ethical. ${ }^{19}$ The two situations most pertinent to the burn victim are 'no benefit' where the child can survive but with a future prognosis of an 'impossibly poor life', and 'no purpose' where the disease is so severe that treatment delays death without alleviation of suffering.

Further implications for treatment were that she was under the legal age to make a medical decision. The new Children's Act 38 of 2005 (the Act) states that the parents have the right to give consent to treatment. ${ }^{20}$ Consequently, since the mother requested maximum therapy, her decision was respected. Even if a child is older than 12 and mature enough to make a decision, the parents are required to assist in giving surgical consent. This does not mean that the parents' decision is definitive. The Act includes a new principle called 'Children's Participation' that gives more weight to children's decision if they are over the age of 12 and are mature. Nevertheless, there are many provisions that allow for the hospital to give consent regardless of a refusal. The Act makes it clear that, in all probability, the overriding principle in all decisions regarding the child is the 'best interest' principle. Section 9 of the Act and also section 28 of the constitution require that best interest be of 'paramount importance'. We therefore had to proceed with resuscitation as it was our considered opinion that this was in her best interest. 


\section{Pitfalls that may influence responsible and rational decisions}

Valid decisions can only be made with correct and sufficient information and knowledge from experience, otherwise a wrong diagnosis and the possibility of withdrawal may follow. To eliminate the risk of this kind of major failure, all role-players should reach consensus. With technical advances, it may also become more difficult to determine when care is likely to confer benefit to the patient or to cause more harm. A final pitfall is when physicians focus on keeping a patient alive without full consideration of the outcome - which should be re-evaluated daily. The focus of benefit then shifts from the patient to the physicians, rendering them incompetent to make legal and ethical decisions for the child.

\section{What did we achieve?}

This child was one of 99 survivors from a major life-threatening burn (TBSA $>50 \%$ ) seen at our institution over the past decade, albeit the most extensively burnt to date. Her injuries left her physically disfigured and scarred. She needed prolonged rehabilitation, and the damage to her outer appearance could influence her quality of life. ${ }^{21-24}$ The outcome of her journey was therefore dependent on many different factors: family, the community and rehabilitation. Ultimately, it will depend on her own reconstruction of a personal life-map, internal acceptance of her 'self' and the strength of changing relationships for her to overcome her burn experience. After 6 years of readjustment and rehabilitation, she is now fully integrated and accepted into society, enrolled in a mainstream school with good peer relationships, well balanced and confident, and participating in sports and debating societies. Her minor residual physical restrictions do not significantly impair her quality of life. This favourable outcome was achieved largely by the concentration of skills in a regional paediatric burns unit.

\section{Conclusion}

As senior clinicians, it is our responsibility to guide the Health Department to develop a rational and fair dispensation for patients with a major/critical thermal injury. ${ }^{11,18}$ The South African Burn Society should formulate guidelines to help doctors, parents and everyone involved to make decisions that are ethical, correct and accountable, and that allow flexibility for each unique case. These guidelines must cover all aspects of the complex decision and be the best available option. ${ }^{3}$

If comfort care is decided upon, it must be realised that even severe burns do not result in immediate deterioration and death. ${ }^{22}$
Risk factors and criteria for comfort care must therefore be specific and ethically acceptable. Our experience over many years has identified burn patients who should be offered quality end-of-life care only: those where the probability of survival is less than $10 \%$, the location and severity of the burn (destructive full-thickness facial and hand burns) would result in extreme disability, and there is irreversible hypoxic brain damage and multi-organ failure. Under these circumstances, open communication, support for the family, shared decision making, relief of pain, continuation of care and grief and bereavement support are essential, ${ }^{25}$ with palliative and pain care services within the institution of great assistance. ${ }^{24,25}$

1. Matzopoulos RE, ed. 2004. A Profile of Fatal Injuries in South Africa. Fifth Annual Report of the National Injury, Mortality Surveillance System. Cape Town: University of Cape Town and the MRC Crime, Violence and Injury Lead Program, 2004

2. Benatar SR, Fleischer TE. Editorial. S Afr Med J 2003;93(6):433-434

3. Medical Futility in End-of-Life Care. Report of the Council on Ethical and Judicial Affairs. JAMA 1999; 281(10):937-941

Young ER. The Laing Essay 1998: Ethical issues in burn care. Burns 1999:25:193-206.

5. Karpelowsky JS, Wallis L, MacAfee A, Rode H. South African Burn Society burn stabilization protocol. S Afrowsy JS, Wallis L, Mach

6. Sheridan RL, Hinson MI, Liang MH, et al. Long-term outcome of children surviving massive burns. JAMA 2000; 283(1):69-73.

7. Barret J, Desai M, Herndon D. Survival in paediatric burns involving $100 \%$ total body surface. Annal of Burns and Fire Disasters 1999;12(3):139-141.

Wolf SE, Debroy M, Herndon DN.The cornerstones and directions of pediatric burn care. Pediatr Surg Int 1997;12:312-320.

9. Anzarut A, Chen M, Shankowsky, H. Quality-of-life and outcome predictors following massive burn injury. Plast Reconstr Surg 2005;116(3):791-797.

10. Rashid A, Khanna A, Gowar JP, Bull JP. Revised estimates of mortality from burns in the last 20 years at the Birmingham Burns Centre. Burns 2001;27:723-730.

1. Hadorn DC. Setting health care priorities in Oregon. JAMA 1991;265:2218-2225

12. Landman WA, Henley LD. Tensions in setting health care priorities for South Africas's children. Med Ethics 1998:24:268-273.

13. Benatar S, Engelbrecht B. Western Cape Department of Health. An Ethical Framework for Decisionmaking. Cape Town: Western Cape Department of Health, 2009.

4. Burns JP, Truog RD. Futility: a concept in evolution. Chest 2007;132:1987-1993.

15. Blakeney P, Meyer W III, Robert R, Desai M, Wolf S, Herndon D. Long-term psychosocial adaptation of children who survive burns involving $80 \%$ or greater total body surface area. J Trauma 1998;44:625634 .

16. Rumsey N, Harcourt D. Body image and disfigurement: issues and interventions. Body Image 2004;1:83-97.

17. Bass MJ, Phillips LG. Economics of pediatric burns. J Craniofacial Surg 2008;19:888-890.

18. Millar PL. Application of a model to guide ethical decision making in burn treatment. Burn Care Rehabil 2000;21:433-438.

19. Royal College of Paediatrics and Child Health. Withholding or Withdrawing Life Saving Treatment in Children. A Framework for Practice. 2nd ed. London: RCPCH, May 2004.

20. Jamieson L, Proudlock P, Chetty M. The Childrens Act No. 38 of 2005. A Guide for Health Care Practitioners, 2nd ed. Cape Town: The Children's Institute, UCT, 30 July 2008.

21. Sanford AP. The Ethical Dimensions of Burn Care. In: Herndon DN, ed.Total Burn Care. St Louis, Miss. Saund

22. Brewster LP, Bennett, BK, Gamelli RL. Application of rehabilitation ethics to a selected burn patien population's perspective. J Am Coll Surg 2006;203:766-771.

23. Kdnigova R. Quality of Life in Burn Victims: A Holistic Approach. Presented at the 8th Congress of the European Burns Association in Marathon,1999. R Hermans Lecture.

24. O'Mara MS, Chapyak D, Greenhalgh DG, et al. End of life in the pediatric burn patient. J Burn Care Res 2006;27:803-808

5. Truog RD, Meyer EC, Burns JP. Toward intervention to improve end-of-life care in the pediatric intensive care unit.Crit Care Med 2006;34(11):S373-379. 